\title{
Eating Good and Moving Like We Should: A Consideration for Registered Dietitians in Schools
}

\author{
Kathy B. Knight, ${ }^{1,{ }^{*}}$ Janie W. Cole, ${ }^{1}$ Lacy M. Dodd, ${ }^{1}$ and Charlotte B. Oakley ${ }^{1}$ \\ ${ }^{1}$ Department of Nutrition and Hospitality Management, University of Mississippi, University, MS, USA \\ "Corresponding author: Kathy B. Knight, Department of Nutrition and Hospitality Management, University of Mississippi, University, MS, USA. Tel: +662-9157371, Fax: \\ +662-9157039, E-mail: kknight@olemiss.edu
}

Received 2016 October 19; Revised 2016 November 22; Accepted 2016 November 26.

\begin{abstract}
Background: While teachers and school nurses may not be able to provide nutrition education to students because of their other duties, registered dietitians have the necessary training in counseling, nutrition education, nutrition therapy, and food service management to be effective at childhood obesity prevention.

Objectives: The purpose of eating good and moving like we should(EGMLWS), a school-based intervention, was to create a successful program to prevent and reduce childhood obesity in the Mississippi Delta by providing nutrition education by a registered dietitian. Methods: The subjects were 1,891 third (school year 2012 - 2013) and fourth graders (2013 - 2014) in 7 Mississippi schools in the north Mississippi River Delta region. The school-based nutrition and physical activity education program was designed to address overweight and obesity in the Mississippi Delta and north Mississippi regions by helping children make healthier nutrition and physical activity choices. The registered dietitian provided nutrition education and consulted to make school menus healthier and more appealing. Pre-and post-school year heights and weights were measured.

Results: Paired t-tests showed significantly lowered mean BMI in 5 schools $(\mathrm{P}<0.05)$; no change in 2 schools and no change over all schools, although all schools had individuals with decreased BMI.

Conclusions: School-based nutrition interventions that feature a registered dietitian can make an impact. The EGMLWS program improved the nutrition knowledge and nutrition-related attitudes of north Mississippi Delta third and fourth graders and significantly improved BMI in 5 of 7 schools.
\end{abstract}

Keywords: Registered Dietitian, School-Based Nutrition Intervention, Childhood Obesity

\section{Background}

As stated by Zylke and Bauchner (1) the recent reports of the prevalence of obesity in the United States (US) (2) "are neither good nor surprising". While obesity rates have decreased in children aged 2 to 5 years from $13.9 \%$ in 2003 - 2004 to $9.4 \%$ in 2013 - 2014, they have remained stable for children aged 6 to 11 years at around 17\% since 2007 - 2008, and increased for adolescents aged 12 to 19 years from $10.5 \%$ in 1993 - 1994 to $20.6 \%$ in 2013 - 2014 (2). Mississippi persistently has some of the highest rates of childhood obesity in the nation; the prevalence of overweight and obesity for all K-12 students was $41.8 \%$ as compared to $40.9 \%$ in 2011 (3) and has some of highest rates for hypertension, atherosclerosis, and diabetes $(4,5)$.

Most of the progress against childhood obesity, seen in many states, has been with Caucasian children (6). African American youth across all age groups are more likely to be obese, are at greater risk for chronic diseases, and are more likely to become unhealthy adults than their white counterparts $(5,7)$. The underlying causes of child health disparities in Mississippi can be tied to the complex inter- play of the multiple social determinants of child health $(\mathrm{SDCH})$, including the environment in which children are born, grow, live, learn, and play (8). Another causative factor is lack of access to healthcare services (9).

Currently, about 30,000 nurses serve in the 110,000 elementary schools of the US (10), and national survey data from the school health policies and programs study shows that school health services are mostly delivered by nurses (11). However, the data also indicate that most services are rendered to individual students and that most nurses do not have the time to run obesity prevention programs (12). After a systematic review, Wainwright et al. (9) concluded that although there is a need for quality research to provide evidence of the clinical effectiveness of school nursing, that the traditional roles: health assessment, first aid, and support of children with diagnosed medical conditions such as asthma or epilepsy are well documented in nursing literature. The researchers then report that although school nurses are now being asked to take a role in health promotion, that little evidence has been documented of any activity toward this effort.

In its recent position paper on pediatric obesity (13), 
the academy of nutrition and dietetics advocates for "multilevel approaches that involve various components or sectors of influence" and suggests that registered dietitians play a role in these interventions. School-based health initiatives have been effective in addressing health disparities among Mississippi students (14), and a variety of federal and state mandates have been enacted regarding in-school meals, health education, and physical activity $(6,15)$. However, the assessment, implementation, and evaluation components of these legislative actions have tended to be underfunded and difficult for schools to implement, especially in school districts with limited financial resources $(16,17)$. Free nutrition and physical activity curricula are available, but many teachers do not have the time, training, and/or skills to research and use these resources. Child nutrition programs play an important role in children's consumption patterns and have the potential to educate children about eating healthy food (18), but directors have regulations and responsibilities that may limit time to foster creativity and culinary excellence (19). Registered dietitians have the necessary training in counseling, nutrition education, nutrition therapy, and food service management to be very effective at childhood obesity prevention. However, less than $1 \%$ of the child nutrition program directors in Mississippi are registered dietitians, a statistic that is similar in many states. Schoolbased nutrition interventions have shown positive effects on body mass index (BMI) values in elementary children, but mixed results have been reported (20-23), and few interventions have been conducted with African American children (24). Also, as stated by Roseman et al. (25) who recommended multi-component interventions, the opportunities for extended impact in school-based interventions may be limited when faced with the challenges of the school schedule, academic testing, state-mandated curricula, and multiple levels of school administration.

\section{Objectives}

The purpose of this project was to determine if a nutrition education program for Mississippi Delta elementary schools, that featured registered dietitians, would have an effect on the nutrition and physical activity knowledge of the students and their attitudes toward nutrition and physical activity. The main objectives of the program were to:

1. Increase nutrition knowledge of third graders by providing nutrition lesson plans to teachers and showing them how to incorporate that education across the curriculum.

2. Encourage increased fruit and vegetable consumption through the starting and maintenance of school gar- dens and classroom education.

3. Working with school nutrition directors/managers to make school lunch menus healthier and more appealing.

4. Encourage system level change by helping schools meet the criteria for the USDA's Healthier US school challenge (HUSSC) (26), a nationwide program designed to encourage healthier school meals and other foods available at school, based on the dietary guidelines for Americans, physical activity, and nutrition education.

\section{Methods}

Eating Good and Moving Like We Should (EGMLWS), is a school-based nutrition and physical activity education program designed to address overweight and obesity in the Mississippi Delta and north Mississippi regions by helping children make healthier nutrition and physical activity choices. The University of Mississippi Institutional Review Board and (when existing) the review boards of the school districts involved approved the research protocol and associated activities.

\subsection{Subjects}

The subjects were 1,891 third (school year 2012 - 2013) and fourth graders (2013 - 2014) in 7 Mississippi schools in the north Mississippi River Delta region. Baseline characteristics can be found in Table 1 . The group was fairly even with regards to gender with $53.02 \%$ males $(n=1,003)$ and $46.98 \%$ females $(n=888)$, but not with regards to race (83.5\% African American, 10.7\% white, and 5.8\% Hispanic).

As shown in Figure 1, when pre-intervention BMIs were sorted according to age- and gender-specific percentiles, 18 males (1.81\%) were underweight (below the 5th percentile), $428(42.72 \%)$ were in the normal range between the 5 th and 85th percentiles, 222 (22.13\%) were overweight (between the 85th and $95^{\text {th }}$ percentiles, and 335 (33.34\%) were classified as obese (above the $95^{\text {th }}$ percentile). Pre-intervention, 21 (2.36\%) girls were underweight, 436 (49.14\%) were normal weight, 166 (18.62\%) were overweight, and 265(29.88\%) were obese.

In the spring of 2012, superintendents of all school districts in the northern half of the Mississippi Delta region were sent an introductory email with a brief description of the project and a request for an appointment to explain the project further. Seven schools in 6 school districts agreed to all the program's components, including: a 15-minute nutrition education class once per week, two 5-minute classroom physical activity sessions per day, the start-up of a school garden, a review of school breakfast and lunch menus by the project's registered dietitian, and 
Table 1. Baseline Demographic Characteristics of Participants ${ }^{\mathrm{a}}$

\begin{tabular}{|c|c|}
\hline Variable & Overall Sample $(n=1,891)$ \\
\hline Age, $y$ & $8.4 \pm 0.4$ \\
\hline \multicolumn{2}{|l|}{ Gender } \\
\hline Males $(n=1003)$ & 53.02 \\
\hline Females $(n=888)$ & 46.98 \\
\hline \multicolumn{2}{|l|}{ Ethnicity } \\
\hline White & 10.7 \\
\hline Black & 83.5 \\
\hline Hispanic & 5.8 \\
\hline \multicolumn{2}{|l|}{ Height (inches) } \\
\hline Total $(n=562)$ & $54.16 \pm 3.15$ \\
\hline Minimum - maximum & $45.13 \pm 65.63$ \\
\hline Males & $54.01 \pm 2.90$ \\
\hline Females & $54.33 \pm 3.40$ \\
\hline \multicolumn{2}{|l|}{ Weight (lbs.) } \\
\hline Total & $83.75 \pm 26.81$ \\
\hline Minimum - maximum & $45.8 \pm 216.0$ \\
\hline Males & $82.46 \pm 24.15$ \\
\hline Females & $87.34 \pm 29.35$ \\
\hline
\end{tabular}

${ }^{\mathrm{a}}$ Values are expressed as Means $\pm \mathrm{SD}$ or (\%).

collection of heights and weights at the beginning and ending of the school year. Although the schools varied in size (which led to a variation in sample sizes, all 7 schools were in districts that were located in rural counties, had more than 90 percent of their students eligible for free or reduced school lunch, and had student populations that were more than 80 percent African American (27). The students in all schools went to physical education classes once per week.

\subsection{Measures}

Data was collected from pre-and post-surveys designed to measure student knowledge and determine nutritionrelated attitudes and eating behaviors. The surveys were administered at the beginning of the school year (during the last week of August) and at the end of the nutrition education for the school year (the last week in April). The survey questtions are found in Tables 2 and 3. Pre-and postschool year heights and weights were measured during the first full month (September) and the last full month (May). Heights were measured using a portable wall-mounted measuring tape (white stature meter height measure measuring tape $200 \mathrm{~cm} / 2 \mathrm{M}$ ). Weights of the children, in light clothing and without shoes, were measured to the nearest 0.1 pound with a portable digital scale (Tanita HD-384 digital scale).

\subsection{Procedure}

EGMLWS, a multi-faceted program, designed to reinforce nutrition and healthy eating messages in a variety of ways, was conducted in 7 schools during the 2012 - 14 school years. Third and fourth graders were subjects the first year, but only The EGMLWS project team included an associate professor who managed data analysis, a registered dietitian who taught nutrition classes in the classrooms, and a health education specialist who coordinated the program. All project staff members provided nutrition lesson plans to teachers, helped schools to start and maintain school gardens, and taught cooking classes to children and parents.

Implementation of the nutrition education involved preparation of lesson plans, development and delivery of teacher training, modeling the instruction and evaluation of student knowledge. Lesson topics were developed from the selected consumer messages of ChooseMyPlate.gov (28) and from the nutrition education resources on the Mississippi Department of Education's Office of Healthy School's website. One main theme was selected for each month of the school year, and included topics like "Make half your grains whole.", "Vary the colors of your fruits and vegetables.", and "Go lean with protein" (28). Then lesson plans for each week were developed by the EGMLWS project team, which included a registered dietitian and a health education specialist. At the beginning of each school year, the dietitian and health education specialist conducted 1hour training with the third-and fourth-grade teachers on 


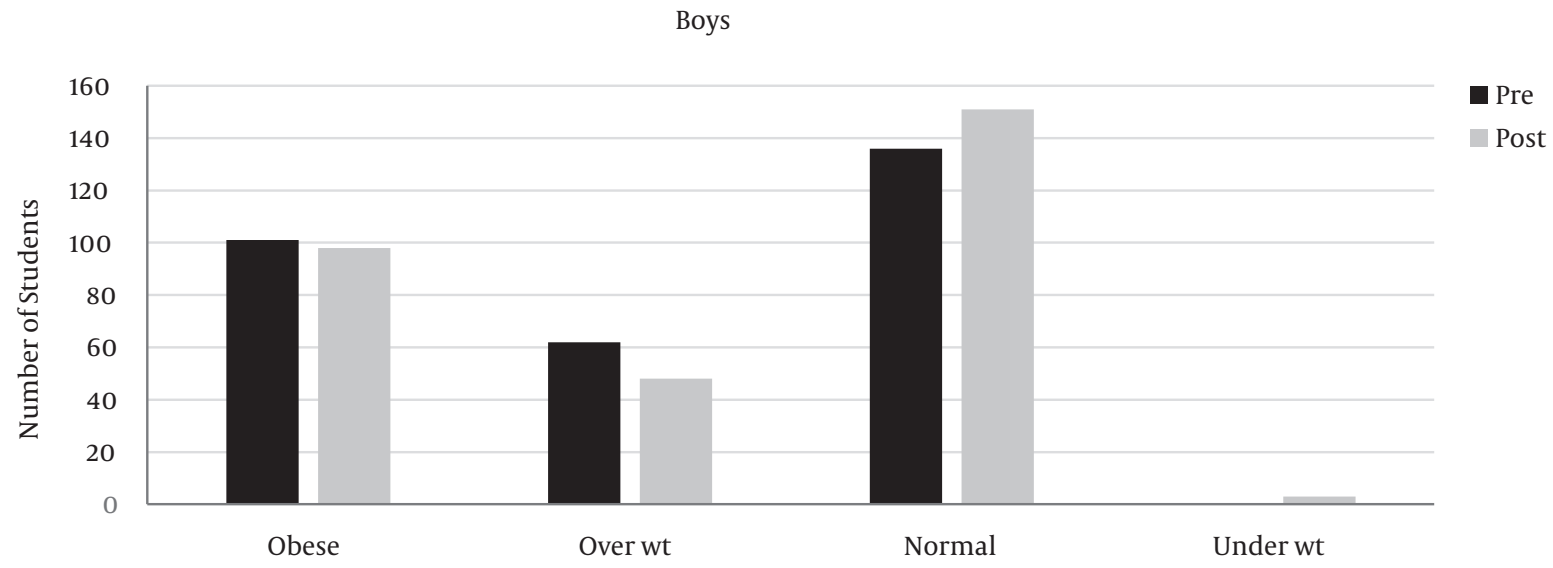

Girls

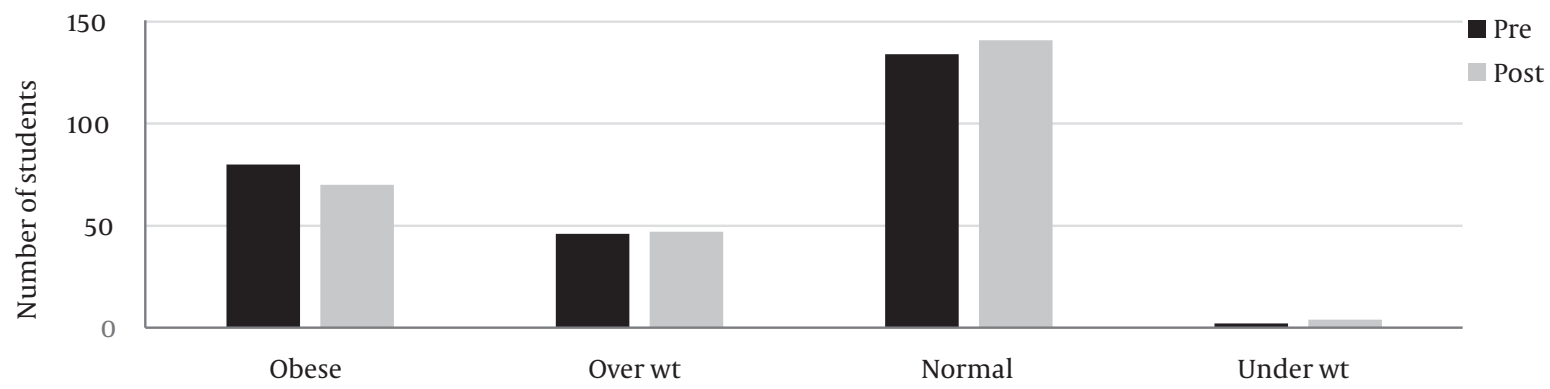

Figure 1. Pre-Vs. Post-Intervention Percentages of Participants by BMI Weight Percentile

Table 2. Differences Between Pre- and Post-Intervention Measures of Nutrition and Physical Activity Attitudes and Behaviors When Evaluated Using t-Test

\begin{tabular}{|c|c|c|c|}
\hline Measured Responses & Pre-Eating Good (Percent Responses), $n=1,891$ & Post-Eating Good (Percent Responses), $\mathrm{n}=1,891$ & P Value \\
\hline 1. I want to eat healthy. & 37.8 & 62.2 & 0.045 \\
\hline 2. I would snack on vegetables. & 25.9 & 56.4 & 0.039 \\
\hline 3. I would eat fruit for a snack. & 42.4 & 90.4 & $<0.001$ \\
\hline 4. I shared nutrition lessons with family. & 16.5 & 53.4 & $<0.001$ \\
\hline 5. I have exercised with my family. & 19.6 & 66.4 & $<0.001$ \\
\hline
\end{tabular}

how to deliver the nutrition lessons. The registered dietitian delivered the lessons every other week, and the teachers delivered the lessons on alternate weeks.

As another part of the nutrition and physical activity education, fruit and vegetable gardens were started at each school. Sizes and styles varied depending on the amount of land that was available and the level of support provided by the school's teachers, parents, and staff. Teachers brought their classes out at least once per week to plant, observe growth, and perform other work such as pulling weeds and hoeing around the plants. On average, the gar- dens were 15 feet wide by 20 feet long and contained 4 to 6 raised beds with soil that was enhanced with peat moss and fertilizer. EGMLWS provided seeds and some start-up plants and the lumber for the raised beds. In 3 schools project staff built the raised beds as well. Parents or other volunteers built the others.

All the menus for the schools' child nutrition programs were reviewed by the EGMLWS registered dietitian. In addition to verifying that the menus met the nutrition standards in the national school lunch and school breakfast programs (29), the registered dietitian reviewed ven- 
Table 3. Differences Between Pre- and Post-Intervention Measures of Nutrition and Physical Activity Knowledge When Evaluated Using t-Test

\begin{tabular}{|c|c|c|c|}
\hline Measured Responses & Pre-Eating Good (Percent Responses), $n=1,891$ & $\begin{array}{c}\text { Post-Eating Good (Percent Responses), } \mathbf{n}= \\
\mathbf{1 , 8 9 1}\end{array}$ & P Value \\
\hline $\begin{array}{l}\text { 1. Eating healthy food is only important for } \\
\text { overweight people. }\end{array}$ & 82.4 & 23.9 & $<0.001$ \\
\hline $\begin{array}{l}\text { 2. Exercise is only important for overweight } \\
\text { people. }\end{array}$ & 71.1 & 15.6 & $<0.001$ \\
\hline 3. I do not have to get diabetes. & 26.4 & 73.6 & $<0.001$ \\
\hline 4. A diet is the food you eat daily. & 32.4 & 78.4 & $<0.001$ \\
\hline $\begin{array}{l}\text { 5. You have to go to the gym to get physical } \\
\text { activity. }\end{array}$ & 54.9 & 22.5 & $<0.001$ \\
\hline $\begin{array}{l}\text { 6. Correct identification of fiber on a food } \\
\text { label. }\end{array}$ & 33.7 & 73.9 & $<0.001$ \\
\hline $\begin{array}{l}\text { 7. Correct identification of calories on a food } \\
\text { label. }\end{array}$ & 27.8 & 79.8 & $<0.001$ \\
\hline
\end{tabular}

dor invoices to monitor prices paid for food, and checked the USDA Foods Available list(30) to see if some foods could be ordered through the USDA food and nutrition service food distribution program. Although most of the menus already conformed to the USDA meal pattern requirements (29), the registered dietitian worked with the child nutrition program directors to make modifications to decrease excess calories and/or increase acceptability of the food.

\subsection{Statistical Analysis}

Demographic data and beginning heights and weights were analyzed using descriptive statistics, and body mass index (BMI) was calculated for each child. BMI is an index of body mass divided by the square of height expressed as $\mathrm{kg} / \mathrm{m}^{2}$ and provides a relative weight that allows comparisons of weight between individuals or between an individual and an ideal weight. Because in those individuals between 2 and 20 years of age, height and therefore weight often change rapidly with age, BMI will not necessarily provide the best measure of comparisons (31). However, BMI in children are often classified according to age and gender specific percentiles of the general population, which is easy for the general public to understand (32). All statistical analysis was conducted using IBM SPSS Statistics for Macintosh, Version 23.0.

\section{Results}

Measurement of pre-and post-year heights and weights in seven schools indicated that $27 \%$ of the students had some decrease in BMI from 2012 to 2014. Twenty-five percent of the 160 students in school 1 had a significant decrease based on paired t-test with a $\alpha=0.05$. Other decreases seen were $47.62 \%$ ( $n=21$ of 44 students) in school $2,10.02 \%$ ( $\mathrm{n}=20$ of 200 students) in school 3, $108.18 \%$ ( $n=33$ of 306 students) in school 4 , and $28.47 \%$
( $\mathrm{n}=295$ of 1035 students) in school 5. ( $\alpha=0.05$ for all). Although $35.71 \%(n=28)$ of 78 students in school 6 and $15.71 \%(n=11)$ of 68 students in school 7 showed decreased BMIs, the differences were not significant.

While obesity rates for African-American Mississippi students has increased every year since 2005 (24), the primarily African-American population of this study demonstrated a shift from obesity to overweight and from overweight to normal. When sorted according to age- and gender-specific percentiles, as was done with the preintervention BMIs, post intervention, the numbers shifted to $10(1.00 \%)$ underweight (below the $5^{\text {th }}$ percentile), 503 $(50.17 \%)$ in the normal range between the $5^{\text {th }}$ and $85^{\text {th }}$ percentiles, $171(17.05 \%)$ overweight (between the $85^{\text {th }}$ and $95^{\text {th }}$ percentiles, and 319 (31.78\%) obese (above the 95th percentile). Post intervention, 14 (1.54\%) girls were underweight, 478 (53.81\%) were normal weight, 159 (17.94\%) were overweight, and 237 (26.71\%) were obese.

As seen in Table 2, pre- and post-intervention measures of nutrition and physical activity attitudes and behaviors showed a movement toward healthier habits. All measured responses showed significant $(P<0.001$ to 0.05 ) shifts toward answers that indicated healthier attitudes and behaviors. However, eating fruit for a snack started out as a more popular choice and became even more popular than choosing vegetables. Exercising with the family started out and became more popular than sharing nutrition lessons with them.

Knowledge increased significantly $(\mathrm{P}<0.001)$ for every question when pre- and post-intervention nutrition and physical activity knowledge was measured. Before intervention, $82.4 \%$ of respondents thought that good nutrition was only important in the obese. Following the program, $76.1 \%$ of those children responded that everyone should eat healthfully. Prior to the program, $71.1 \%$ of children responded that physical activity was more important for 
overweight people than anyone else. After, 85\% indicated that physical activity was important for everyone. Also, the number of children who indicated they thought they could prevent themselves from getting diabetes increased from $26.4 \%$ of all responses to $73.6 \%$ of all responses.

Although all the wellness coordinators of the participating school districts were aware of the HUSSC and were interested in completing the application, they did have questions about the application and only one school had achieved bronze level. All the coordinators took advantage of the individualized training for the HUSSC process from EGMLWS program staff with each school receiving an average of 3.2 hours of coaching. Only 3 of the 7 schools actually submitted their applications. One school reached bronze medal level.

\section{Discussion}

The purpose of EGMLWS was to create a successful program to prevent and reduce childhood obesity in the Mississippi Delta. This program was a multi-component school-based nutrition intervention conducted during the 2012 - 2014 academic years. The results reported here describe the program's effectiveness in decreasing the BMIs and improving nutrition related attitudes, behaviors, and knowledge.

Significant numbers of students achieved decreases in BMI in 5 of the 7 schools. Also, although no significant difference was found in BMI across all schools, there was no significant increase, and each school had students with some decrease in BMI with the percentages ranging from $15.71 \%$ to $47.62 \%$. In addition, the percentages of obese participants decreased for both boys (33.34\% preintervention to $31.78 \%$ post-intervention) and girls (29.88\% pre-intervention to $26.71 \%$ post-intervention).

These results supported the findings of several systematic reviews of school-based nutrition interventions, which report moderate evidence of BMI reduction $(24,25)$. One of these reviews, Lavelle et al. (33) found that interventions that targeted overweight/obese children reduced their BMI by 0.35 (95\% CI: 0.12, 0.58, P = 0.003). Those delivered to all children reduced BMI by 0.16 (95\% CI: 0.06, 0.25, $\mathrm{P}=0.002$ ). After conducting a randomized controlled trial, Gortmaker et al. (34) reported that planet health, a schoolbased intervention, led to a reduction in the prevalence of obesity among girls $(\mathrm{P}<0.05)$, but not for boys.

The nutrition education that was delivered by the registered dietitian and the classroom teachers also had an impact. The children were not only eager to learn about nutrition (as reported by both teachers and the dietitian), they did learn. Knowledge increased significantly $(\mathrm{P}<$ 0.001) for every question when pre- and post-intervention nutrition and physical activity knowledge was measured, and pre- and post-intervention measures of nutrition and physical activity attitudes and behaviors showed a movement toward healthier habits. Studies have shown that increases in knowledge and attitudes can lead to desired health behaviors. In a randomized controlled trial in 47 fourth-grade California classrooms (1713 students), Larsen et al. (35) tested program efficacy, and a secondary analysis of archival data tested program dissemination. The program featured seven nutrition lessons delivered by classroom teachers over a 4- to 10-week time period. Child nutrition knowledge and attitudes and parent willingness to serve new foods were positively affected, and consumption of low-nutrient high-density foods and sugar-sweetened beverages decreased while consumption of proteins and grains increased.

It should be noted that although the project targeted $3^{\text {rd }}$ and $4^{\text {th }}$ grade teachers and classrooms, all of the schools housed other grades and their teachers also received the training, because it was conducted as the schools' teacher professional development. The registered dietitian was also invited to these classrooms as a guest speaker and to do healthy food tastings. Some of the teachers from other grades in each school incorporated the lesson plans. Heights and weights of the children in the other grades were not recorded due to constraints on researchers' time and personnel.

Although only 3 of the 7 wellness coordinators submitted HUSSC applications, all made progress in identifying areas of strength and weakness in their health policies. Most cited lack of nutrition education for all students and daily physical activity as the primary factors for not being able to qualify. The 3 applications that were submitted used EGMLWS for the nutrition education component, and this helped one school earn its bronze medal level certification.

One of the most appreciated services of the registered dietitian was the review of the schools' menus and production records. She was able to suggest healthier ways to cook certain foods, ways to make foods taste better, and how to save money by using foods from the USDA's food distribution program. This service supports domestic nutrition programs and American agricultural producers through purchases of domestic agricultural products for use in schools and institutions, and applications may be made to receive food at no cost to the child nutrition program. All the schools were able to trim their food budget as a result of these consultations with the registered dietitian, but for one school the outcome was dramatic. Through the use of the USDA food distribution program and suggestions about the type of foods purchased, the registered dietitian was able to save the school $\$ 30,000$ 
from its annual food budget for the 2012 - 2013 school year. Although the results of our study showed lowering or maintaining of BMI in schools that are more than $80 \%$ African Americans, there were limitations. First, the lack of a control group of schools renders the results less reliable than those from a randomized controlled trial. Sample sizes from each school varied because of the differences in the size of the schools. Also, we did not observe every teacher providing nutrition education, and while we have no reason to believe otherwise, we cannot categorically confirm that all nutrition education sessions or physical activity breaks were executed to the standards set forth in the teacher training or modeled by our team. Geographical distances may have interfered with the amount of programming delivered by the program as with Prelip et al. (36). Also, lack of researchers' time, teachers' and school's schedules, and the need for individual interviews with third-grade children did not allow for repeat collection of data on multiple days. Waist circumference and percent body fat data were also not collected, likely reducing impact of the intervention. Results were not categorized by race because 3 of the schools had student populations that were greater than 99\% African American and the overall sample population was 83.5\% African American. Because the study was conducted in the rural Mississippi Delta region, results may not be generalizable to schools in urban locations or that have a more diverse student population.

Although the prevention of childhood obesity is challenging, especially in areas with fewer resources, schoolbased nutrition interventions that feature a registered dietitian can make an impact. The EGMLWS program improved the nutrition knowledge and nutrition-related attitudes of north Mississippi Delta third and fourth graders and significantly improved BMI in 5 of 7 schools. This, with the fact that BMI did not raise over all schools and that there was some lowering of BMI in every school is encouragement that school-based interventions can favorably impact BMI in primarily African American populations. School-based interventions that feature registered dietitians show promise in the prevention of childhood obesity, but more research is needed to identify the components that are most successful in impacting behavior change.

\section{Footnotes}

Authors' Contribution: Study concept and design: The study was developed and designed by Kathy Knight and Charlotte Oakley; acquisition of data: Janie Cole and Lacy Dodd collected the data; analysis and interpretation of data: Kathy Knight analyzed the data; drafting of the manuscript: Dr. Knight drafted the manuscript; critical revision of the manuscript for important intellectual content: All Authors helped revise the manuscript; statistical analysis: Dr. Scott Knight performed the statistical analysis; administrative, technical, and material support: All authors contributed this support; study supervision: Drs. Knight and Oakley helped supervise the study.

Funding/Support: The study was funded as a part of eating good and moving like We Should, an on-going schoolbased nutrition intervention program conducted by the Department of nutrition and hospitality management at the University of Mississippi. Eating good and moving like we should was supported by the W.K. Kellogg foundation under grant \# P3023331.

\section{References}

1. Zylke JW, Bauchner H. The Unrelenting Challenge of Obesity. JAMA. 2016;315(21):2277-8. doi: 10.1001/jama.2016.6190. [PubMed: 27272578].

2. Ogden CL, Carroll MD, Lawman HG, Fryar CD, Kruszon-Moran D, Kit BK, et al. Trends in Obesity Prevalence Among Children and Adolescents in the United States, 1988-1994 Through 2013-2014. JAMA. 2016;315(21):2292-9. doi: 10.1001/jama.2016.6361. [PubMed: 27272581].

3. Centers for Disease Control and Prevention. Childhood Obesity Facts Centers for Disease Control and Prevention; 2016. Available from: http://www.cdc.gov/healthyschools/obesity/facts.htm.

4. Mississippi Center for Obesity Research . Obesity in Mississippi Mississippi Center for Obesity Research; 2016. Available from: https://www. umc.edu/Administration/Centers_and_Institutes/Mississippi_ Center_for_Obesity_Research/Obesity_in_Mississippi.aspx.

5. Zhang L, Kolbo JR, Kirkup M, Molaison EF, Harbaugh BL, Werle N, et al. Prevalence and trends in overweight and obesity among Mississippi public school students, 2005-2013. J Miss State Med Assoc. 2014;55(3):80-7. [PubMed: 24834609].

6. Center for Mississippi Health Policy . Mississippi School Nutrition Environment Evaluation Data System (MS NEEDS) Center for Mississippi Health Policy; 2016. Available from: http: //www.mshealthpolicy.com/wp-content/uploads/2013/10/MSNEEDS-Comparison-Report-Y1-Y4.pdf.

7. Kolbo JR, Zhang L, Molaison EF, Harbaugh BL, Hudson GM, Armstrong MG, et al. Prevalence and trends in overweight and obesity among Mississippi public school students, 2005-2011. J Miss State Med Assoc. 2012;53(5):140-6. [PubMed: 23252146].

8. Marmot M, Friel S, Bell R, Houweling TA, Taylor S, Commission on Social Determinants of $\mathrm{H}$. Closing the gap in a generation: health equity through action on the social determinants of health. Lancet. 2008;372(9650):1661-9. doi: 10.1016/S0140-6736(08)61690-6. [PubMed: 18994664].

9. Wainwright $\mathrm{P}$, Thomas J, Jones $\mathrm{M}$. Health promotion and the role of the school nurse: a systematic review. J Adv Nurs. 2000;32(5):1083-91. [PubMed: 11114992].

10. Bradley BJ. The school of nurse as health educator. $J$ Sch Health. 1997;67(1):3-8. doi: 10.1111/j.1746-1561.1997.tb06287.x. [PubMed: 8990040].

11. Kubik MY, Story M, Davey C. Obesity prevention in schools: current role and future practice of school nurses. Prev Med. 2007;44(6):5047. doi: 10.1016/j.ypmed.2007.02.013. [PubMed: 17451804].

12. Baisch MJ, Lundeen SP, Murphy MK. Evidence-based research on the value of school nurses in an urban school system. $J$ Sch Health. 2011;81(2):74-80. doi: 10.1111/j.1746-1561.2010.00563.x. [PubMed: 21223274]. 
13. Hoelscher DM, Kirk S, Ritchie L, Cunningham-Sabo L, Academy Positions C. Position of the Academy of Nutrition and Dietetics: interventions for the prevention and treatment of pediatric overweight and obesity. J Acad Nutr Diet. 2013;113(10):1375-94. doi: 10.1016/j.jand.2013.08.004. [PubMed: 24054714]

14. Kolbo JR, Penman AD, Meyer MK, Speed NM, Molaison EF, Zhang L. Prevalence of overweight among elementary and middle school students in Mississippi compared with prevalence data from the Youth Risk Behavior Surveillance System. Prev Chronic Dis. 2006;3(3):84. [PubMed: 16776885].

15. Mississippi Healthy Students Act . Mississippi Healthy Students Act; 2016. Available from: http://billstatus.ls.state.ms.us/documents/ 2007/pdf/SB/2300-2399/SB2369SG.pdf.

16. Buffington A, McKee C, Ragsdale K, Blanchard TC, Baggett D, Southward LH. Impact of Mississippi healthy students act of 2007 on district- and school-level health policies: school officials' perspectives. J Sch Health. 2014;84(5):285-93. doi: 10.1111/josh.12152. [PubMed: 24707922].

17. Parcel GS, Perry CL, Kelder SH, Elder JP, Mitchell PD, Lytle LA, et al. School climate and the institutionalization of the CATCH program. Health Educ Behav. 2003;30(4):489-502. doi: 10.1177/1090198103253650. [PubMed:12929899].

18. Welker E, Lott M, Story M. The School Food Environment and Obesity Prevention: Progress Over the Last Decade. Curr Obes Rep. 2016;5(2):145-55. doi: 10.1007/s13679-016-0204-0. [PubMed: 27066793].

19. Briggs M, Fleischhacker S, Mueller CG, American Dietetic A, School Nutrition A, Society for Nutrition E. Position of the American Dietetic Association, School Nutrition Association, and Society for Nutrition Education: comprehensive school nutrition services. J Nutr Educ Behav. 2010;42(6):360-71. doi: 10.1016/j.jneb.2010.08.007. [PubMed: 21070977].

20. Silveira JA, Taddei JA, Guerra PH, Nobre MR. The effect of participation in school-based nutrition education interventions on body mass index: a meta-analysis of randomized controlled community trials. Prev Med. 2013;56(3-4):237-43. doi: 10.1016/j.ypmed.2013.01.011. [PubMed: 23370048].

21. Safron M, Cislak A, Gaspar T, Luszczynska A. Effects of school-based interventions targeting obesity-related behaviors and body weight change: a systematic umbrella review. Behav Med. 2011;37(1):15-25. doi: 10.1080/08964289.2010.543194. [PubMed: 21347906].

22. Naylor PJ, Nettlefold L, Race D, Hoy C, Ashe MC, Wharf Higgins J, et al. Implementation of school based physical activity interventions: a systematic review. Prev Med. 2015;72:95-115. doi: 10.1016/j.ypmed.2014.12.034. [PubMed: 25575800].

23. Aloia CR, Shockey TA, Nahar VK, Knight KB. Pertinence of the recent school-based nutrition interventions targeting fruit and vegetable consumption in the United States:a systematic review. Health Promot Perspect. 2016;6(1):1-9. doi: 10.15171/hpp.2016.01. [PubMed: 27123430].

24. Robinson LE, Webster EK, Whitt-Glover MC, Ceaser TG, Alhassan S. Effectiveness of pre-school- and school-based interventions to impact weight-related behaviours in African American children and youth: a literature review. Obes Rev. 2014;15 Suppl 4:5-25. doi: 10.1111/obr.12208.
[PubMed: 25196404]

25. Roseman MG, Riddell MC, Haynes JN. A content analysis of kindergarten-12th grade school-based nutrition interventions taking advantage of past learning. J Nutr Educ Behav. 2011;43(1):2-18. doi: 10.1016/j.jneb.2010.07.009. [PubMed: 21216364].

26. United State Department of Agriculture Food and Nutrition Service . HealthierUS School Challenge: Smarter Lunchrooms USA: United State Department of Agriculture Food and Nutrition Service; 2016 Available from: http://www.fns.usda.gov/hussc/healthierus-schoolchallenge-smarter-lunchrooms.

27. Mississippi School District Demographic Profiles . Proximity 2016. Available from: http://proximityone.com/ms_sdc.htm.

28. United State Department of Agriculture Food and Nutrition Service . Getting Started with MyPlate 2016. Available from: http: //www.choosemyplate.gov/sites/default/files/printablematerials/ GettingStartedWithMyPlate.pdf.

29. United State Department of Agriculture Food and Nutrition Service Nutrition Standards in the National School Lunch and School Breakfast Programs USA: United State Department of Agriculture Food and Nutrition Service; 2016. Available from: https://www.gpo.gov/fdsys/ pkg/FR-2012-01-26/pdf/2012-1010.pdf.

30. United State Department of Agriculture Food and Nutrition Service USDA Foods Available List USA: United State Department of Agriculture Food and Nutrition Service; 2016. Available from: http://www. fns.usda.gov/fdd/foods-expected-be-available.

31. Must A, Anderson SE. Body mass index in children and adolescents considerations for population-based applications. Int J Obes (Lond) 2006;30(4):590-4. doi: 10.1038/sj.ijo.0803300. [PubMed:16570087].

32. Flegal KM, Ogden CL, Wei R, Kuczmarski RL, Johnson CL. Prevalence of overweight in US children: comparison of US growth charts from the Centers for Disease Control and Prevention with other reference values for body mass index. Am J Clin Nutr. 2001;73(6):1086-93. [PubMed: 11382664].

33. Lavelle HV, Mackay DF, Pell JP. Systematic review and meta-analysis of school-based interventions to reduce body mass index. $J$ Public Health (Oxf). 2012;34(3):360-9. doi: 10.1093/pubmed/fdr116. [PubMed: 22267291].

34. Gortmaker SL, Peterson K, Wiecha J, Sobol AM, Dixit S, Fox MK, et al. Reducing obesity via a school-based interdisciplinary intervention among youth: Planet Health. Arch Pediatr Adolesc Med. 1999;153(4):409-18. doi: 10.1001/archpedi.153.4.409. [PubMed: 10201726].

35. Larsen AL, Robertson T, Dunton G. RE-AIM analysis of a randomized school-based nutrition intervention among fourth-grade classrooms in California. Transl Behav Med. 2015;5(3):315-26. doi: 10.1007/s13142015-0311-6. [PubMed: 26327937].

36. Prelip M, Slusser W, Thai CL, Kinsler J, Erausquin JT. Effects of a schoolbased nutrition program diffused throughout a large urban community on attitudes, beliefs, and behaviors related to fruit and vegetable consumption. J Sch Health. 2011;81(9):520-9. doi: 10.1111/j.1746 1561.2011.00622.x. [PubMed: 21831064]. 